Hispania, 2021, vol. LXXXI, n. ${ }^{\circ}$ 269, septiembre-diciembre, págs. 827-853 ISSN: 0018-2141, e-ISSN: 1988-8368, https://doi.org/10.3989/hispania.2021.022

\title{
Víctimas de Defensa Interior. La violencia anarquista contra la dictadura y sus consecuencias (1962-1965)*
}

\author{
Gaizka Fernández Soldevilla ${ }^{1}$ \\ Centro Memorial de las Víctimas del Terrorismo \\ investigacion@centromemorialvt.com
}

\begin{abstract}
RESUMEN: En 1962 el movimiento libertario español creó Defensa Interior, un organismo que empleó la violencia para intentar acabar tanto con la dictadura de Francisco Franco como con la vida del propio dictador. Esta organización cometió atentados terroristas en España y ciertos puntos de Europa entre 1962 y 1963, aunque sobre el papel su historia se prolongó hasta 1965. El saldo de sus bombas fue una persona muerta y 35 heridas. En este artículo se arroja luz sobre la vida de quienes sufrieron la violencia de Defensa Interior. Así, la biografía de su única víctima mortal nos sirve para ilustrar tanto su fracaso como las consecuencias de su estrategia.
\end{abstract}

\footnotetext{
* Este artículo se ha realizado en el marco del programa de investigación del CMVT (Centro Memorial de las Víctimas del Terrorismo), del GIR Humanidades y Ciencias Sociales en la Era digital y tecnológica de la Universidad Isabel I y del proyecto de investigación de la Universidad del País Vasco PGC2018-094133-B-100, financiado por el Ministerio de Ciencia e Innovación, la Agencia Estatal de Investigación y el Fondo Europeo de Desarrollo Regional, Unión Europea.

Siglas de archivos: Archivo Histórico Nacional, Madrid (AHN); Archivo General e Histórico de Defensa, Madrid (AGHD); Archivo General de la Administración, Alcalá de Henares, Madrid (AGA); Centro Documental de la Memoria Histórica, Salamanca (CDMH); y Juzgado Togado Militar Territorial n. ${ }^{\circ}$ 43, Burgos (JTMT43).

El autor desea agradecer las útiles sugerencias, correcciones y aportaciones de María del Carmen Alba, que fue quien redescubrió el caso de Manuel Eleuterio Liáñez, José Luis de la Granja, Raúl López Romo, Liviana Bucureșteanu, Antonio Rivera, Juan Francisco López Pérez, Francisco Grajal Torres, José Francisco Briones Aparicio, Lorenzo Castro, Jesús Espinosa, T. Serna, el servicio de documentación del periódico $A B C$, el Archivo Municipal de Huelva y la Dirección General de Apoyo a Víctimas del Terrorismo del Ministerio del Interior, Gobierno de España.
}

${ }^{1}$ ORCID ID: https://orcid.org/0000-0002-7574-1159

Copyright: (C) 2021 CSIC. Este es un artículo de acceso abierto distribuido bajo los términos de una licencia de uso y distribución Creative Commons Reconocimiento 4.0 Internacional (CC-BY 4.0) 


\section{Palabras clave: víctimas del terrorismo, terrorismo, Defensa Inte- rior, anarquismo, dictadura, Francisco Franco.}

Victims of Defensa Interior. Anarchist violence against the dictatorship and its consequences (1962-1965)

ABSTRACT: In 1962 the Spanish libertarian movement created Defensa Interior, a group that resorted to violence to end Francisco Franco's dictatorship and the life of the dictator himself. This organization committed terrorist attacks in Spain and certain parts of Europe between 1962 and 1963, although it existed on paper until 1965. The casualties inflicted by the anarchist bombs resulted in one person dead and 35 injured. This article sheds light on the lives of those who suffered the violence of Defensa Interior. Thus, the biography of its sole fatality serves to illustrate both the failure of the group and the consequences of its strategy.

KEY WORDS: victims of terrorism, terrorism, Defensa Interior, Anarchism, dictatorship, Francisco Franco.

CÓMO CITAR ESTE ARTÍCULO / CITATION: Fernández Soldevilla, Gaizka, «Víctimas de Defensa Interior. La violencia anarquista contra la dictadura y sus consecuencias (19621965)», Hispania, 81/269 (Madrid, 2021): 827-853. https://doi.org/10.3989/hispania.2021.022.

Víctimas ha habido siempre, pero hasta ahora eran invisibles porque se las consideraba el precio obligado de la marcha de la historia.

MATE, 2006: 5.

\section{INTRODUCCIÓN}

Tras la guerra civil (1936-1939), en la que habían contado con el apoyo del Eje, los sublevados instauraron en España una dictadura acaudillada por el general Francisco Franco. Se basaba tanto en la despiadada represión contra los leales al gobierno republicano como en el sostén de un importante sector de la sociedad. Ahora bien, la derrota de la Alemania de Hitler en la II Guerra Mundial (1939-1945) pareció poner en peligro al régimen franquista. Esperando una pronta intervención extranjera, el PCE (Partido Comunista de España) y otras fuerzas de izquierdas impulsaron guerrillas ${ }^{2}$.

La Guerra Fría permitió la supervivencia de la dictadura, que se presentó como un dique contra el avance del comunismo. En 1952 España ingresó en la UNESCO (Organización de las Naciones Unidas para la Educación, la Ciencia y la Cultura). Al año siguiente, firmó el Concordato con el Vaticano y los

\footnotetext{
2 SERRANO, 2001. ESPINOSA MAESTRE, 2010.
} 
acuerdos con Estados Unidos. En 1955 fue aceptada en la ONU (Organización de las Naciones Unidas). El presidente de EEUU Dwight D. Eisenhower visitó Madrid en diciembre de 1959. Unos meses antes, el gobierno había aprobado el Plan de Estabilización y, luego, el primer Plan de Desarrollo, que, en una coyuntura internacional favorable, permitirían un fuerte crecimiento durante la década de los sesenta. El régimen se había consolidado. En 1961 celebró por todo lo alto el «XXV Aniversario del Alzamiento Nacional» y en 1964 haría lo propio con los «XXV Años de Paz» ${ }^{3}$.

Según Lorenzo Castro, se hizo «patente, a los ojos del exilio, la imposibilidad de un cambio en España forzado por la presión internacional, de una solución "diplomática" al franquismo». Tales circunstancias hacían que la estrategia guerrillera perdiese sentido. A finales de los años cuarenta el PCE abandonó este tipo de violencia armada. En junio de 1956 apostó por restablecer una democracia parlamentaria por medio de la política de «Reconciliación Nacional» ${ }^{4}$.

Huérfana del liderazgo comunista y cada vez más acosada por las FOP (Fuerzas de Orden Público), la guerrilla antifranquista entró en un inexorable declive. A principios de la década de los sesenta lo que quedaba del maquis cometió sus últimas acciones. La noche del 3 al 4 de enero de 1960, en la provincia de Gerona, el teniente de la Guardia Civil Francisco de FuentesFuentes y Castilla-Portugal fue asesinado por el anarquista Francisco Sabaté Llopart (Quico), a quien al día siguiente mató un somatén. El 9 de agosto de 1961, siguiendo órdenes de Valentín González González (El Campesino), un grupo de guerrilleros intentó sabotear la central eléctrica del pantano de Irabia (Orbaiceta, Navarra). Se topó con una pareja de la Benemérita. En el tiroteo murió el guardia civil Luis Moreno Ortega y resultó herido su compañero5.

El crepúsculo del maquis coincidió con la aparición en América latina y Francia de pequeñas organizaciones armadas que estaban compuestas por veteranos de la guerra civil y por jóvenes que no habían luchado en ella. Denunciando la aparente pasividad de la oposición antifranquista mayoritaria y de las instituciones republicanas en el exilio, se inspiraban en el derrocamiento de las dictaduras de Marcos Pérez Jiménez en Venezuela (1958) y, sobre todo, de Fulgencio Batista (1959) en Cuba. En ese sentido, algunos grupos aspiraban a reproducir el exitoso modelo guerrillero de Fidel Castro y Ernesto Che Guevara. Otros, en cambio, se aferraban a la ya antigua estrategia anarquista de la «propaganda por el hecho». De cualquier manera, casi todos ellos acabaron practicando el terro-

${ }^{3}$ MORADIELLOS, 2018.

${ }^{4}$ CASTRO, inédito.

${ }^{5}$ Información sobre estos sucesos en los Boletines de la Brigada de Investigación Social de 1961, AHN, FC-Ministerio de Interior, Policía H, exp. 53102. 
rismo ${ }^{6}$. Cabe mencionar a la Unión de Combatientes Españoles (1958-1960), el Movimiento Español 1959 (1959-1963), el DRIL (Directorio Revolucionario Ibérico de Liberación) (1960-1964), Defensa Interior (1962-1965), el Movimiento por la III República y por la reconstitución del Ejército Republicano (1963-1967) y el Frente Español de Liberación Nacional (1963-1970)7.

Estas organizaciones cometieron atentados tanto en España como en el extranjero, pero en su mayoría no pasaron de lo que Eduardo González Calleja ha calificado como «aventurismo armado», es decir, «una violencia de bajo nivel técnico practicada por militantes no especializados, con un carácter puntual y un propósito meramente publicitario» ${ }^{8}$. Valga como muestra un botón. Entre junio de 1963 y junio de 1964 Andrés Ruiz Márquez (el coronel Montenegro) colocó en Madrid 68 artefactos explosivos de reducida potencia, casi petardos, en nombre del Frente Español de Liberación Nacional del exministro Julio Álvarez del Vayo. Fue detenido en junio de 1964. Al mes siguiente sería sentenciado a muerte, aunque se le conmutó la pena máxima por otra de reclusión mayor?.

Dos grupos, el DRIL y Defensa Interior, alcanzaron cierta notoriedad por el coste humano de sus actos de violencia y la consiguiente represión de la dictadura. En total, sus atentados sumaron tres víctimas mortales y decenas de heridos. Sus propios errores produjeron la muerte de uno de sus activistas. Y la acción punitiva de la justicia franquista acabó con la ejecución de otros tres.

El DRIL era una organización, formada por españoles y portugueses, que llevó a cabo tres grandes operaciones en las que arrebató la vida a dos personas y lesionó a otras diez. En febrero de 1960 un comando puso cuatro bombas en Madrid. No causaron víctimas, pero uno de los miembros del DRIL falleció al detonar su propio artefacto y otro fue fusilado tras un juicio sumarísimo. Entre el 26 y el 29 de junio de 1960 el norte de España sufrió una nueva cadena de explosiones. El 27, una bomba estalló en la estación de tren de Amara (San

${ }^{6}$ Podemos definir «terrorismo» como el tipo de violencia armada que busca un efecto psicológico, político y simbólico superior al de los simples daños materiales y personales producidos por sus atentados. Una «organización terrorista» sería un grupo clandestino de pequeño tamaño que carece de control sobre un territorio propio y que emplea la violencia terrorista como principal estrategia para conseguir sus objetivos políticos. Véanse GONZÁLEZ CALLEJA, 2017 y FERNÁNDEZ SOLDEVILLA, 2021. También https://glosariovt.com/

${ }^{7}$ La mayor contribución del politólogo David C. RAPOPORT (2004), hoy aceptada por casi toda la comunidad académica (GONZÁLEZ CALLEJA, 2013), ha consistido en identificar las cuatro oleadas de terrorismo que hemos sufrido desde 1880: la nihilista / anarquista, la nacionalista / anticolonial, la de la nueva izquierda y la fundamentalista religiosa. Los grupos aquí comprendidos están a caballo entre el segundo y el tercer ciclo, aunque tienen más que ver con este último. Más información sobre la tercera oleada de terrorismo en AVILES, AZCONA y RE, 2019. Una panorámica general del fenómeno en España en AVILÉS, 2010 y FERNÁNDEZ SOLDEVILLA, 2021.

${ }^{8}$ GONZÁLEZ CALLEJA, 2013: 429.

${ }_{9} A B C$, Madrid, 24 de junio, 8 de julio y 12 de julio de 1964. 
Sebastián), provocando seis heridos, entre ellos la niña Begoña Urroz, que falleció al día siguiente. En enero de 1961 un comando del Directorio secuestró el trasatlántico portugués Santa María. Durante el ataque los asaltantes hirieron a un pasajero, al practicante de piloto y a João José do Nascimento Costa, el joven tercer piloto del buque, que murió poco después. El último documento del DRIL que se conserva data del 24 de noviembre de $1964^{10}$.

El declive del Directorio se solapó con la actividad de Defensa Interior, que utilizaba métodos similares, por lo que no es de extrañar que a veces se confundiera a ambas organizaciones. Ahora bien, no había relación directa entre ambas $^{11}$. Defensa Interior era un grupo anarquista que mató a una persona e hirió a otras 35. Dos de sus activistas fueron ejecutados tras un proceso que ha suscitado muchas dudas. El caso recibió cierta atención de la prensa a partir de 1996, cuando se solicitó su revisión. Además de los artículos y entrevistas que se publicaron en aquel momento, existen interesantes textos sobre la trayectoria de este colectivo, desde estudios académicos, como los del historiador Ángel Herrerín, a literatura militante, pasando por libros periodísticos y memorias de los protagonistas de los hechos. Sin embargo, casi todos ellos convierten en protagonistas a los miembros de Defensa Interior. Y tienen poco en cuenta a sus víctimas ${ }^{12}$.

Utilizando fuentes bibliográficas, archivísticas y orales, la presente investigación pretende poner el foco en los seres humanos que fueron objeto de su violencia. Se trata, por tanto, de colocar a los damnificados en la centralidad de un relato sustentado en la metodología del historiador. El primer apartado, introductorio, es una breve crónica de la trayectoria de Defensa Interior. En el segundo se reconstruye la biografía de su única víctima mortal, Manuel Eleuterio Liáñez, producida en junio de 1962. En el último se analiza el atentado que esta organización cometió en la DGS (Dirección General de Seguridad) en julio de 1963, dando voz a la herida que salió peor parada, Carmen Anguita.

\section{Bombas ANARQuistas}

La guerra civil y la represión franquista fueron devastadoras para el movimiento libertario español, compuesto por la CNT (Confederación Nacional del Trabajo), la FAI (Federación Anarquista Ibérica) y la FIJL (Federación Ibérica

10 FERNÁNDEZ SOLDEVILLA y AGUILAR, 2019.

11 Algunos militantes del DRIL eran anarquistas. Según ALBEROLA y GRANSAC, 2004: 42, el secuestro del Santa María «causó un profundo impacto» en los antifranquistas de corte libertario «y afirmó las tendencias activistas».

${ }^{12} \mathrm{La}$ falta de atención a las víctimas del terrorismo ha sido un fenómeno generalizado en la literatura académica hasta hace relativamente poco, como ha estudiado JIMÉNEZ, 2017; 2020. 
de Juventudes Libertarias). No obstante, en los años cuarenta los ácratas lograron reorganizarse $y$, en algunos casos, impulsaron ciertas formas de violencia política. A mediados de la década siguiente, cuando se hizo patente el afianzamiento de la dictadura, la CNT renunció a la «acción directa», aunque algunos maquis continuaron operando por su cuenta ${ }^{13}$.

En aquel momento el anarquismo español atravesaba una profunda crisis. Por razones ideológicas, estratégicas y generacionales, se encontraba dividido en dos facciones: una ortodoxa y otra posibilista. Para acabar con el cisma, entre agosto y septiembre de 1961 se celebró el II Congreso Intercontinental en Limoges (Francia), en el cual se decidió la reunificación de la CNT y la constitución de una alianza con el sindicato socialista UGT (Unión General de Trabajadores) y el nacionalista STV (Solidaridad de los Trabajadores Vascos). También se aprobó un dictamen reservado: la creación de Defensa Interior. A decir de Ángel Herrerín, aquel paso respondía tanto al peso de los partidarios de la violencia, mayoritariamente encuadrados en Juventudes Libertarias, como a la aparente «fe del converso» de quienes hasta entonces se habían opuesto a ella. Cabría añadir que en la historia del anarquismo había minoritarios pero significativos precedentes del recurso al terrorismo ${ }^{14}$.

La meta de Defensa Interior eran reactivar la «lucha armada» contra el régimen y, a ser posible, asesinar a Franco, algo que los ácratas ya habían intentado varias veces. En cierto modo, se trataba de recoger el testigo de la «propaganda por el hecho» y el malogrado maquis. Defensa Interior dependía de una comisión formada por los secretarios de la CNT, la FAI y la FIJL, pero, en la práctica, estuvo propulsada por los más jóvenes: hijos de anarquistas exiliados como Octavio Alberola, quien ya había participado en el Movimiento Español 1959, y emigrantes salidos de España en busca de trabajo. Primero implícitamente y luego de manera abierta, otro sector del movimiento libertario se resistiría al empleo de la violencia. Entre otras razones, porque temía que, si se descubría que se utilizaba Francia para preparar los atentados, la CNT fuese ilegalizada en aquel país. Se pretendió conjurar tal posibilidad reivindicando algunas de las bombas en nombre de un fantasmal Consejo Ibérico de Liberación, lo que no engañó a nadie ${ }^{15}$.

El movimiento libertario recuperó antiguos depósitos de armas y explosivos que la Resistencia francesa había escondido tras la II Guerra Mundial. Ahora bien, gran parte del material estaba en estado defectuoso, por lo que también

13 HERRERÍN, 2004.

${ }^{14}$ HERRERÍN, 2004: 239. El dictamen en GURUCHARRI e IBÁÑEZ, 2010: 289-291. Sobre la relación entre los anarquistas y la violencia terrorista véanse AVILÉS y HERRERÍN, 2008 y AVILÉS, 2013.

15 HERRERÍN, 2006. 
se recurrió a la compra de armamento a traficantes en el mercado negro ${ }^{16}$. En mayo de 1962 la dirección de Defensa Interior acordó que al mes siguiente se perpetrarían los primeros atentados. Entre esa fecha y junio de 1963 cerca de 40 artefactos estallaron tanto dentro como fuera de España. Sus objetivos eran variados: el Vicariato General Castrense, sucursales bancarias, colegios mayores, la casa consistorial de Valencia, delegaciones del Instituto Nacional de Previsión, oficinas del sindicato vertical, postes de la línea eléctrica, la carretera al palacio de Ayete, sedes de periódicos, el gobierno militar de Guipúzcoa, aviones de Iberia, etc. La prensa responsabilizó al DRIL de algunas de aquellas bombas, cuando no a agentes comunistas, pero fueron colocadas por Defensa Interior. También llevó su sello la explosión que el 13 de junio de 1962 acabó con la vida de un hombre en la calle de Sagasta de Madrid ${ }^{17}$.

El domingo 12 de agosto de 1962 otra carga detonó en la basílica del Valle de los Caídos. Según $A B C$, el artefacto había sido ocultado «bajo uno de los bancos destinados a los fieles, que están cerca del Altar Mayor y próximos a la capilla del Santísimo». No hubo damnificados, ya que la bomba estalló «poco después de terminada la misa que se celebra los días festivos a las seis de la tarde $»^{18}$. Los autores materiales del sabotaje habían sido el perito electricista Antonio Martín Bellido y el anarcosindicalista francés Paul Desnais. No obstante, las FOP arrestaron a Francisco Sánchez Ruano, que había estado visitando el lugar con unos amigos extranjeros en el momento del suceso. En su casa se encontró propaganda antifranquista. Bastó para que fuese condenado a 28 años de cárcel, de los que cumpliría 11. El verdadero culpable, Martín Bellido, no se planteó entregarse: «No arreglaba nada. Nunca lo habrían soltado. No me arrepiento. Son cosas que pasan en una guerra. Yo en ese momento pensaba en otras acciones $\rangle^{19}$.

En realidad, el atentado del Valle de los Caídos no era más que una forma de desviar la atención de las autoridades mientras, en San Sebastián, otro comando llevaba a cabo su plan más ambicioso: matar a Franco. Desde la perspectiva libertaria, relatan Octavio Alberola y Ariane Gransac, era «la acción que se consideraba podría ser decisiva». Miembros de ETA (Euskadi ta Askatasuna, Euskadi y Libertad) habían trasladado los explosivos por la frontera hispanofrancesa, pero allí terminó su papel en la operación, que fue diseñada y ejecutada por Defensa Interior. Los anarquistas colocaron una bomba de unos veinte kilogramos en la cuneta de la cuesta de Aldapeta, en la carretera de San

16 GURUCHARRI e IBÁÑEZ, 2010: 74.

17 ABC, 14, 16 y 17 de junio de 1962. Oficina de Prensa Euzkadi, París, 18 de junio de 1962. El Diario Vasco, San Sebastián, 4 de diciembre de 1962. Los propios miembros de Defensa Interior han reconocido la autoría de estos atentados en sus obras.

${ }^{18} A B C, 14$ de agosto de 1962.

19 El Pais, Madrid, 5 de noviembre de 2004. 
Sebastián a Hernani, para hacerla estallar cuando el dictador subiese al Palacio de Ayete, en el que pasaba parte de las vacaciones de verano. Sin embargo, como aquel año Franco retrasó su llegada a la ciudad y la batería se estaba agotando, el comando decidió detonar el artefacto el 19 de agosto. Según la crónica de $A B C$, «los daños materiales se redujeron a la rotura de algunos cristales de una villa particular y de un noviciado de monjas en las proximidades del solitario lugar $\rangle^{20}$. Horas más tarde, se produjeron explosiones en las sedes de los diarios Ya (Madrid), Pueblo (Madrid) y La Vanguardia Española (Barcelona). Dos empleados de este periódico, Rufino Calvo y Jesús Gay Medrano, sufrieron lesiones. Sospechando su implicación en aquellos atentados, la Policía arrestó a algunos integrantes de ETA y del FLP (Frente de Liberación Popular), que no habían tenido nada que ver ${ }^{21}$.

En septiembre de 1962 las FOP detuvieron a militantes de Defensa Interior, que fueron acusados de las bombas de aquel verano. Para presionar contra una eventual condena a muerte, el día 28 de septiembre un grupo anarquista italiano secuestró a Isu Elías, vicecónsul honorario general de España en Milán. El rehén recobró la libertad a los cuatro días. Finalmente, un consejo de guerra sentenció a decenas de años de cárcel a los libertarios ${ }^{22}$.

Pese a todo, la actividad terrorista de Defensa Interior continuó. El 2 de diciembre de 1962, informaba el correspondiente sumario, hubo «una violenta explosión (...) en el edificio del Gobierno Militar de esta Plaza [San Sebastián], originada por un artefacto colocado en un hueco de ventilación del dormitorio de tropa, causando roturas de cristales y desperfectos, sin desgracias personales». Los ciudadanos donostiarras, se podía leer en El Diario Vasco, «no olvidan casos similares anteriores, entre ellos uno que costó, en la estación de Amara, la vida a una inocente niña de corta edad». $A B C$ culpaba directamente al DRIL de la explosión. Sin embargo, fue reivindicada por el Consejo Ibérico de Liberación, que también reclamó los atentados contra el Colegio de Abogados de Valencia, el Tribunal de Cuentas del Reino en Madrid, el consulado español en Amsterdam y el Palacio de Justicia de Lisboa ${ }^{23}$.

En el primer semestre de 1963 Defensa Interior puso bombas en varios aviones de Iberia en aeropuertos tanto de España como de otros puntos de Europa occidental. Uno de los aparatos empezó a arder justo antes de despegar. También fueron objeto de atentados otros medios de transporte, como el ferry Barcelona-Mallorca. De igual manera, los anarquistas atacaron oficinas

20 ALBEROLA y GRANSAC, 2004: 89. BATISTA, 2015: 65-69. ABC, 21 de agosto de 1962.

${ }^{21} A B C, 21$ de julio de 1962. Boletín Informativo de la Brigada de Investigación Social, $\mathrm{n}^{\circ}{ }^{9}$ 9874/ XXV, 20 de septiembre de 1962, AHN, Fondos Contemporáneos, M. Interior - Policía H, exp. 53103.

${ }^{22} A B C, 23$ de septiembre de 1962.

${ }^{23}$ Causa $n^{\circ}$ 168/62 del Juzgado Militar Eventual de San Sebastián, JTMT43. El Diario Vasco, 4 de diciembre de 1962 y $A B C, 4$ de diciembre de 1962. 
de Iberia y del CSIC (Consejo Superior de Investigaciones Científicas) o la Embajada de EEUU ${ }^{24}$.

El 29 de julio de 1963 un comando de Defensa Interior colocó dos artefactos en Madrid. Uno estalló en la Delegación Nacional de Sindicatos, sin causar víctimas. El otro, en la DGS, donde dejó 31 heridos. Las FOP arrestaron a dos sospechosos, Joaquín Delgado y Francisco Granado, a los que se incautaron 20,9 kilogramos de explosivo plástico, una granada, una pistola Colt del calibre 45, una metralleta, 89 cartuchos de pólvora negra, dos bengalas, mecha, un radiorreceptor y un transmisor. Tras un juicio sumarísimo, en el que se les encontró culpables de estos y otros crímenes, Delgado y Granado fueron condenados a muerte. Se les ejecutó mediante garrote vil el 17 de agosto de $1963^{25}$.

Eran miembros en activo de Defensa Interior que estaban en posesión de un pequeño arsenal, pero sus antiguos compañeros (Octavio Alberola y Félix Villagrasa i Hernàndez), los autores que han estudiado su caso (el periodista Carlos Fonseca y el historiador Ángel Herrerín) y las propias fuentes documentales apuntan a que Joaquín Delgado y Francisco Granado no eran responsables de la bomba de la DGS. Los dos anarquistas tenían la misión de preparar la infraestructura para un nuevo intento de asesinato de Franco, esta vez en el paseo de la Florida, junto al Puente de los Franceses, pero nada más. Haciendo patentes los graves problemas de funcionamiento de Defensa Interior, sus compañeros ni siquiera les habían informado de que había otro comando operando en Madrid. Cuando se produjo el atentado de la DGS ni Granado ni Delgado estaban preparados para huir ${ }^{26}$.

Tuvieron que pasar años para que salieran a la luz los auténticos perpetradores de aquella acción terrorista. Se trataba de otros dos integrantes de Defensa Interior, Sergio Hernández y, de nuevo, Antonio Martín Bellido. Lo han confesado en medios escritos y audiovisuales. Luis Andrés Edo recoge que, tras el ajusticiamiento de sus compañeros, Hernández «cayó en una profunda depresión» por su «complejo de culpabilidad». Como el propio interesado le contó a Carlos Fonseca, «me sentí tan mal durante tanto tiempo que estuve a punto de necesitar tratamiento psiquiátrico. Ahora sólo quiero olvidar». En cambio, Martín Bellido alegó en una entrevista: «Yo era un pequeño militante, aunque lo que he hecho ha causado dramas. Soy uno del montón. Y al ser del mon-

${ }^{24}$ GURUCHARRI e IBÁÑEZ, 2010: 117-119. ABC, 18 de agosto de 1963. La Vanguardia, Barcelona, 24 de agosto de 1963.

${ }^{25} A B C, 30$ de julio y 18 de agosto de 1963. La Vanguardia, 3, 14 y 18 de agosto de 1963. Causa 1118/1963 del Juzgado Especial Nacional de Actividades Extremistas, AGHD. Más información en el Boletín de la Brigada de Investigación Social, 19 de agosto de 1963, disponible en el AHN y en https://www.dropbox.com/s/uxa53zlyk1iwcq5/38.pdf?dl=0

${ }^{26}$ ALBEROLA y VILLAGRASA i HERNÀNDEZ, 2007. FONSECA, 1998. HERRERÍN, 2006

Hispania, 2021, vol. LXXXI, n. ${ }^{\circ}$ 269, septiembre-diciembre, págs. 827-853, ISSN: 0018-2141, e-ISSN: 1988-8368 https://doi.org/10.3989/hispania.2021.022 
tón no soy responsable. Yo hacía lo que me han dicho. Y claro, he buscado salvarme yo también $)^{27}$.

En 1996 la televisión francesa emitió el documental Granado y Delgado. Un crimen legal, de Lala Gomà y Xavier Montanyà, en el que, por primera vez, Martín Bellido reconocía su participación en el atentado de la DGS. A raíz de su emisión, se constituyó el Grupo pro revisión del proceso Granado-Delgado, que pretendía rehabilitar la memoria de estos dos miembros de Defensa Interior, apoyaba la solicitud de una revisión del sumario hecha por sus familiares y exigía la anulación de la sentencia condenatoria de $1963^{28}$. No lo consiguieron, pero el caso concitó la atención de los medios de comunicación y de ciertos sectores políticos.

El impacto emocional de la ejecución de Granado y Delgado, los problemas económicos, la falta de medios, los incuestionables fallos de coordinación, la enérgica represión de las FOP, que se valieron de la información facilitada por un infiltrado policial, y la creciente oposición a la violencia de una parte del movimiento libertario, llevaron a Defensa Interior a la inoperancia ${ }^{29}$. A tal coyuntura hay que sumar que, como respuesta a la preparación en su territorio de aquellas acciones terroristas, las autoridades galas ilegalizaron las Juventudes Libertarias y realizaron redadas policiales contra los anarquistas exiliados. Se cumplían así las previsiones más pesimistas de quienes creían que Defensa Interior iba a poner en peligro su situación en Francia.

En octubre de 1963 Germinal Esgleas y Vicente Llansola fueron elegidos respectivamente secretario general y secretario de coordinación de la CNT, lo que les situaba en los puestos clave de la dirección de Defensa Interior. Irónicamente, ambos eran críticos acérrimos de la violencia que auspiciaba el sector juvenil más radical. No es de extrañar que suspendieran la realización de nuevos atentados, por lo que la actividad del grupo se paralizó. En 1965 el Congreso de Montpellier puso punto y final a la trayectoria de Defensa Interior ${ }^{30}$.

\section{Manuel Eleuterio Liáñez Benítez}

Poco antes de las 11:00 horas de la mañana del miércoles 13 de junio de 1962 se registró una detonación en el andén central de la madrileña calle de

27 EDO, 2006: 390. FONSECA, 1998: 259. La entrevista a Antonio Martín está disponible en https://blocs.mesvilaweb.cat/txemabofill/?p=259466

28 ALBEROLA y VILLAGRASA i HERNÀNDEZ, 2007.

${ }^{29}$ Con excepciones como la del anarquista británico Stuart Christie, que planeó una nueva tentativa de magnicidio contra Franco. Fue detenido en España en agosto de 1964 y condenado a 20 años de prisión, aunque sería excarcelado en septiembre de 1967. Su historia en CHRISTIE, 2005.

${ }^{30}$ HERRERÍN, 2004: 244-259; 2006. 
Sagasta, frente a la delegación del Instituto Nacional de Previsión. Causó la muerte a una persona y heridas leves a otras dos. A las 11:15 el juzgado se constituyó en el lugar de los hechos. Un médico forense examinó el cadáver. Había sufrido la amputación traumática de las dos manos, así como quemaduras y heridas penetrantes en el tronco y la cabeza. Se trataba de un atentado terrorista. Las circunstancias que rodearon el suceso están reflejadas en el sumario que abrió el Juzgado de Instrucción n. ${ }^{\circ} 4$ y, al mes siguiente, continuó el Juzgado Militar Especial Nacional de Actividades Extremistas ${ }^{31}$.

Los dos lesionados eran Antonio Jiménez Espejo y Julián García Sardinero. El primero, un cordobés de 17 años, trabajaba en un concesionario de automóviles. Estaba parado en su bicicleta ante un semáforo en rojo cuando «oyó en el centro del bulevar por detrás de la tómbola allí instalada, una gran explosión, que al principio creyó era motivada por los cables de la red eléctrica, y al mirar al lugar de donde había procedido la explosión vio, en el suelo, en el centro del bulevar, un hombre tumbado boca arriba, con la ropa destrozada y ensangrentado». Jiménez Espejo presentaba una «herida contusa en brazo derecho» y «otra en pierna izquierda». Julián García Sardinero, un industrial de 62 años, natural de Arganda del Rey, se vio afectado por la deflagración de la bomba cuando se dirigía a unos talleres de su propiedad. Tenía una «herida contusa en codo derecho».

José Fernández Eguren, un administrativo de 40 años, intentaba aparcar su motocicleta cuando escuchó «una violenta explosión en el mismo centro del boulevard, unos metros más arriba, y vio una gran desbandada de público y en un círculo que se formó por causa de tal desbandada vio a un hombre tirado en el suelo, mirando hacia arriba, totalmente destrozado». A su lado había una «cartera de cuero, muy vieja y destrozada». Fernández cubrió el cuerpo con «algunos cajones de los que existían en los alrededores, posiblemente de los que utiliza una tómbola, allí instalada». Cuando llegó un policía municipal, se dio aviso a las FOP.

La primera hipótesis fue que a un terrorista le había estallado su propio artefacto $^{32}$. Sin embargo, en opinión del juez instructor, el coronel Enrique Eymar, «a través de todas las declaraciones e informes se ve claramente que [la víctima] no pertenecía a ninguna organización de tal género». Concluyó que «[sin] duda alguna vio el artefacto colocado en una cartera y sin saber de lo que se trataba, como pobre mendigante, se apoderó de ella y al querer manipular en la cartera, para ver qué llevaba, sobrevino la explosión que le causó la muerte». Aunque hay varias explicaciones posibles, la más probable es el hurto. No obstante, la cartera no pudo ser el objeto robado: en el sumario se comprueba que

${ }^{31}$ Causa 974/1962 del Juzgado Militar Especial Nacional de Actividades Extremistas, AGHD.

${ }^{32}$ La Vanguardia, 14 de junio de 1962.

Hispania, 2021, vol. LXXXI, n. ${ }^{\circ}$ 269, septiembre-diciembre, págs. 827-853, ISSN: 0018-2141, e-ISSN: 1988-8368 https://doi.org/10.3989/hispania.2021.022 
era propiedad del muerto, que nunca se desprendía de ella. Por tanto, el artefacto debía estar camuflado en otro lugar o dentro de otro objeto.

Las FOP no tardaron en descubrir la identidad de la víctima: Manuel Eleuterio Liáñez Benítez. A partir de ese momento buscaron e interrogaron a todo aquel que hubiera tenido el más mínimo contacto con él desde la Guerra Civil. Su trabajo nos permite reconstruir una parte de la biografía de Liáñez.

Había nacido en Huelva capital el 18 de abril de 1891. Era el hijo pequeño de Antonio Manuel, empleado, y de María del Carmen. El padrón municipal indica que en 1911 vivía en el número 21 de la calle General Bernal (actual calle La Fuente) con sus padres y un hermano tres años mayor, 1lamado Lucas, de profesión mecánico. En 1917 Manuel Liáñez todavía residía en aquella ciudad, aunque en la calle Santa Fe, n. ${ }^{\circ} 10^{33}$. Constaba como «empleado».

En un momento indeterminado se trasladó a Sevilla, donde trabajó como agente comercial de la Casa Laso. En el Centro Documental de la Memoria Histórica se conservan las cartas que durante los primeros meses de 1936 Manuel Liáñez escribió a personajes destacados de la II República como Diego Martínez Barrio y Luis Nicolau d'Olwer. En ellas, alegando que estaba pasando por una situación «bastante crítica», que había comenzado en 1934, solicitaba trabajo en distintas instituciones e, indirectamente, facilitaba algunos datos sobre su biografía. Así, recordaba a Martínez Barrios que «el año 1935 vine recomendado a Vd. desde Sevilla por nuestro buen amigo Dn. José González Navas [y usted] prometió colocarme en unas plazas que había vacantes en el Congreso, mas surgió la crisis cuando desempeñaba la cartera de Gobernación». Liáñez se declaraba «buen sevillano», como el propio Martínez Barrios, y ferviente partidario de la II República, pidiendo al Gobierno del Frente Popular que se acordase «de los que hemos sufrido toda clase de desprecios, de los que hemos luchado y lucharemos por ella, porque ha sido heredada de nuestros padres y lo que es más, de los veteranos, nuestros abuelos. Derecho, creo, tenemos cuando menos, a no morir de hambre, ya que la hemos conseguido con toda nuestra fuerza». En una misiva mencionaba a su esposa, sin dar su nombre y sobre la que nunca más se vuelve a saber nada ${ }^{34}$.

Probablemente Manuel Liáñez vivía en Madrid desde 1934, ya que ese año conoció en una taberna al jienense Fausto Catalán Sánchez que, como él, militaría después en la CNT. Ya en la guerra civil Liáñez fue responsable de un parque de Intendencia de este sindicato libertario. Años después contó que durante aquella etapa «no le faltaba de comer e incluso facilitaba subsistencias

${ }^{33}$ El dato del padrón de 1911 me fue facilitado por el Archivo Municipal de Huelva. El posterior, en Guía general de Huelva y su provincia, 1917, disponible en http://www.huelva.es/ archivo/BIBLIOTECA_DIGITAL/04416/R_04416-compressed.pdf

${ }^{34}$ Las cartas en CDMH, PS Valencia, C0046, exp. 497, C0049, y exps. 66, 76 y 147, y C0050. 
a amigos y conocidos». Fausto Catalán añadió otro detalle: siempre vio a su amigo armado con una pistola. En ese momento tuvo lugar un episodio revelador: Liáñez le salvó la vida a un desconocido del que le separaba un abismo ideológico. Se trataba de Gregorio Ortiz Palacios, el dueño de un cine en Villaverde Alto, donde había nacido en 1886. Él mismo relató a las FOP que durante la II República era militante del partido católico Acción Popular, núcleo de la CEDA (Confederación Española de Derechas Autónomas) de José María GilRobles. En 1936 había sido detenido por milicianos del Frente Popular, que lo internaron en la checa de Fomento. Temiendo por su vida, el chofer de Gregorio Ortiz Palacios pidió ayuda a Fausto Catalán, a quien conocía previamente. Ambos rogaron a Liáñez que intercediese por el prisionero. Según Catalán, su amigo «inmediatamente se puso a su disposición y les acompañó a Fomento consiguiendo que a don Gregorio Ortiz, que iban a asesinarlo aquella madrugada, lo trasladaran a la Dirección General de Seguridad». Tras pasar por las cárceles de la Modelo y Ventas, gracias a nuevas gestiones de Liáñez, Gregorio Ortiz fue puesto en libertad. Meses después el anarcosindicalista y el derechista fueron presentados formalmente. Tras la guerra civil, se volvieron a ver dos veces más e, incluso, se citaron para una tercera, pero Liáñez nunca apareció. Gregorio Ortiz sabía de él, «por Fausto, que vivía mal y que tenía la intención de acercarse a su domicilio con objeto de que le diera trabajo, pero que no llegó a verle» ${ }^{35}$.

No tenemos más noticias de Liáñez hasta su arresto el 23 de enero de 1959 en Madrid. Se le acusaba de hurto. Pese a carecer de antecedentes, la Jefatura Superior de Policía le consideraba «delincuente habitual contra la propiedad y "descuidero"». En el Juzgado Especial de Vagos y Maleantes el detenido declaró que desde los dieciocho años había trabajado como viajante: entre 1941 y 1943, en la compañía Mata de Málaga y, entre 1955 y 1956, en la Casa Requena e Hijos en Játiva, una fábrica de licores. Desde esa última fecha estaba jubilado «debido a su edad avanzada y por estar [...] enfermo». No obstante, el médico forense que lo examinó lo declaraba «útil para aquellos trabajos en consonancia con su edad». Por añadidura, el apoderado de la Casa Requena e Hijos informó de que Liáñez había estado contratado «como viajante a comisión en el año 1951 y parte de 1952», es decir, que llevaba sin empleo más tiempo del que pretendía. Además, su antiguo jefe contó que «en el referido trabajo que desempeñaba tuvo algunas irregularidades, por cuyo motivo se le despidió». El 14 de abril de 1959 Manuel Liáñez fue condenado a entre dos meses y dos años de internamiento en un «Establecimiento de Trabajo», aunque se le computó el tiempo que había pasado en prisión preventiva y salió a la calle. El 12 de

${ }^{35}$ El sumario judicial que las autoridades republicanas instruyeron contra Gregorio Ortiz Palacios por el delito de Desafección al Régimen entre 1936 y 1937 es el Expediente $n .^{\circ}$ 267, AHN, FC-CAUSA_GENERAL, 326, exp. 32. Puede consultarse online en http://pares.mcu.es/ 
octubre de ese mismo año volvió a ser arrestado, «en actitud de poner en práctica su actividad delictiva de "descuidero"». Él alegó que la detención se había producido en su propio domicilio, por error, y que ya había encontrado trabajo como «comisionista de vinos y de sillas plegables». En noviembre de 1959 el Juzgado Especial le sentenció a entre tres meses y dos años de internamiento, que cumplió en la Colonia Penitenciaria de Nanclares de la Oca (Álava). Fue excarcelado el 11 de febrero de 1960. Permaneció en libertad vigilada dos años, hasta febrero de 1962. Y cuatro meses más tarde murió ${ }^{36}$.

Tan solo dos días después del atentado que acabó con su vida, su historial fue filtrado a la prensa, que lo exageró y tergiversó. Así, Liáñez fue transformado en un «delincuente habitual contra la propiedad, varias veces detenido en Madrid y Sevilla por hurtos y estafas, y al que el año 1959 le fue aplicada la ley de vagos y maleantes $\rangle^{37}$. Además de resaltar la inexactitud de algunos de esos datos, habría que recordar que el caso de Liáñez era sintomático de un problema muy grave y generalizado: la penuria de aquellos años había disparado el índice de delitos contra la propiedad. En 1959 se incoaron 52.697 causas por este motivo (el 44,02\% del total). El año anterior habían sido 48.458 (el 43,51 \%). El posterior, $54.441(\mathrm{el} 44,65 \%)^{38}$.

ImAGEN 1. Fotografías de la ficha policial de Manuel Eleuterio Liáñez

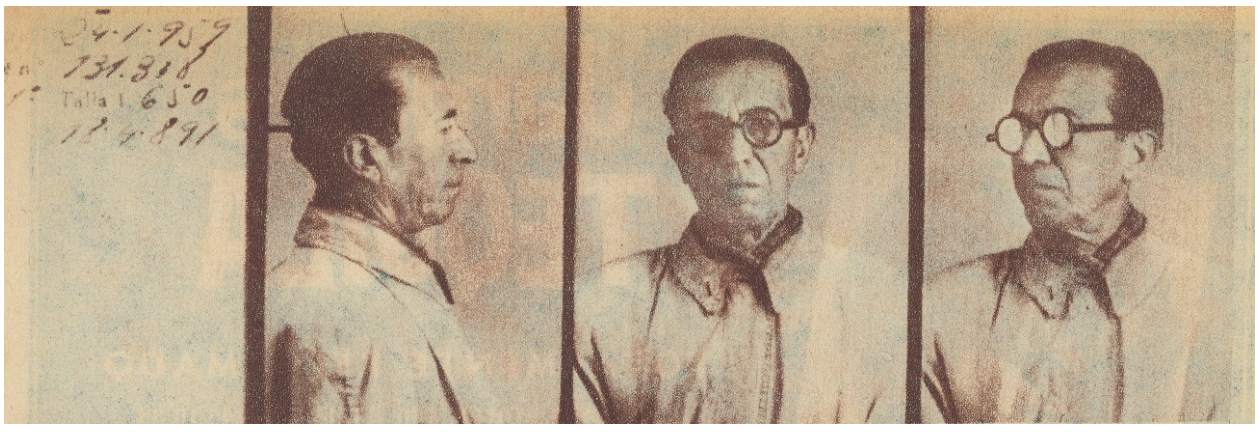

Fuente: Expediente de peligrosidad n. ${ }^{\circ}$ 27/1959 de Manuel Eleuterio Liáñez Bénitez, AGA, 42, 39, legajo 02144.

En 1962 Manuel Liáñez era un anciano solitario de 71 años. Soltero, no tenía familiares directos ni amigos cercanos, al menos en Madrid. Su vida era

${ }^{36}$ Expediente de peligrosidad n. ${ }^{\circ}$ 27/1959 de Manuel Eleuterio Liáñez Bénitez, AGA, 42, 39, legajo 02144.

${ }^{37}$ La Gaceta del Norte, Bilbao, 16 de junio de 1962.

38 ORTIZ HERAS, 2008. 
monótona. Desde primera hora de la mañana, frecuentaba ciertas tabernas, en las que tomaba cazalla o un chato de vino. De algunas se iba enseguida, en otras departía con los parroquianos, especialmente si eran andaluces como él. Pero no intimaba con nadie ${ }^{39}$.

Tanto es así que su cadáver tuvo que ser identificado por Manuela Aguado López, la dueña de la pensión de la calle Calatrava en la que vivía desde noviembre de 1960. Informó a la policía de que su huésped «decía dedicarse a la representación de licores». Era «de carácter muy amable y educado» y «hacía una vida moderada sin que en ningún momento notara nada anormal». Solo «en raras ocasiones» había vuelto a su domicilio «un poco más alegre de lo normal». Jamás le había oído «hablar de política, sino todo lo contrario, que hacía manifestaciones de ser muy católico». Su apoliticismo y religiosidad quedan corroborados por el testimonio de varios conocidos de Liáñez, así como por sus efectos personales, entre los que se encontraron los libros Historia bíblica (1913), Consejero católico (1895) y El alma devota de la santísima eucaristía (1907), todos ellos con su firma. También había misivas dirigidas a diversas personalidades solicitando ropa usada, pequeñas cantidades de dinero o cartas de recomendación, así como gestiones para su ingreso en una residencia. «Yo no pido nada», escribía en un borrador, «pero si tan solo, para sobrellevar mis pocos años de vida, tuviera asegurado un trozo de pan y una cama en cualquiera de los asilos de Madrid, muy principalmente y si fuera posible en la Gran Residencia de Ancianos».

Liáñez cobraba un subsidio de vejez de 400 pesetas mensuales. La habitación que compartía con un camarero separado, sin derecho a comida, le costaba 300 ptas. al mes. Únicamente le quedaban 100. Era imposible subsistir con dicha cantidad. En vez de pedir ayuda al empresario al que había salvado la vida, Manuel acudió a comedores de caridad. También realizaba algunos recados para una señora y su sobrino que vivían en la calle de Sagasta. No sabemos qué hacía «casi diariamente» para la mujer, pero sí para el estudiante de Derecho Adolfo Ruiz de Velasco del Valle: cada miércoles, sobre la una del mediodía, iba hasta su casa para recoger dinero con el que comprarle entradas de conciertos en el Monumental Cinema, que entregaba al día siguiente. Le gratificaban con 30 ptas. a la semana. El joven consideraba a Liáñez «una buena persona, honrada y psicológicamente un tanto "despistado"», así como muy católico. «Asimismo su comportamiento ha sido correctísimo y educado, aunque un tanto charlatán»».

El 13 de junio de 1962 Manuel Liáñez había salido de su pensión a las 9:15 horas. Desde la calle Calatrava a la calle de Sagasta hay unos 35 minutos andando. Podría haber llegado sobre las 9:50, pero su cita semanal con Adolfo

${ }^{39}$ Causa 974/1962, del Juzgado Militar Especial Nacional de Actividades Extremistas, AGHD.

Hispania, 2021, vol. LXXXI, n. ${ }^{\circ}$ 269, septiembre-diciembre, págs. 827-853, ISSN: 0018-2141, e-ISSN: 1988-8368 https://doi.org/10.3989/hispania.2021.022 
Ruiz de Velasco era a mediodía. Ignoramos qué hizo durante la hora escasa que le quedaba de vida. Según el juez instructor, encontró un objeto que parecía olvidado en el Instituto Nacional de Previsión o en otro sitio. Y lo hurtó. Así lo sugieren sus antecedentes y algunos episodios menores que salieron a relucir en la investigación. Por un lado, se había hecho con el cabo de una vela en la iglesia de los santos Justo y Pastor. Por otro, había sido expulsado de una taberna por negarse a pagar su consumición. En ese sentido, es verosímil que, como concluyó el coronel Eymar, el hurto le hubiese llevado a la muerte, aunque cabe añadir que antes la miseria le había empujado al hurto.

El sumario se cerró en diciembre de 1962. No fue noticia. Para entonces hacía mucho que la prensa se había desentendido de Liáñez: concretamente desde que se supo de su historial delictivo. El atentado llevaba el sello de Defensa Interior, pero fue imposible encontrar a los autores materiales. Aquellos anarquistas nunca fueron juzgados por la muerte de su antiguo correligionario. Tampoco hoy conocemos sus nombres ${ }^{40}$.

Manuel Liáñez tardó poco en caer en el olvido. Si bien hay quien ha reivindicado la memoria de Defensa Interior, no se ha hecho lo propio con la de sus damnificados. Liáñez ni siquiera está incluido en la lista de víctimas del terrorismo reconocidas por el Ministerio del Interior ${ }^{41}$. Nadie lo ha solicitado.

\section{Carmen Anguita Abril}

El Ministerio del Interior ha indemnizado a 4.808 heridos por actos terroristas cometidos entre 1960 y la actualidad. La obra Heridos y olvidados, de María Jiménez y Javier Marrodán, nos permite saber el lugar y la fecha del atentado más antiguo con heridos reconocidos oficialmente: Madrid, 29 de julio de 1963. La damnificada era una chica de 16 años $^{42}$. El libro no indica su nombre y apellidos, pero el dato es fácilmente localizable en la hemeroteca. A partir de allí, podemos completar su historia gracias a la causa judicial ${ }^{43}$ y al testimonio oral de la propia víctima, Carmen Anguita ${ }^{44}$.

Nació en Lopera (Jaén) el 29 de noviembre de 1947. Tenía un hermano pequeño, José. Su padre se trasladó a Madrid y le siguió el resto de la familia.

${ }^{40}$ El Ministerio de Gobernación llegó a dar algunos nombres $(A B C, 23$ de septiembre de 1962), pero en el sumario no aparecen pruebas al respecto. Sí estaba clara la responsabilidad de Defensa Interior (Boletín de la Brigada de Investigación Social, 2 de enero de 1963, disponible en AHN y en https://www.dropbox.com/s/ab76600nrug9ejo/31.pdf?dl=0).

${ }^{41} \mathrm{http}: / / \mathrm{www}$.interior.gob.es/fallecidos-por-terrorismo

42 JIMÉNEZ y MARRODÁN, 2019.

${ }^{43}$ Causa 1118/1963 del Juzgado Militar Especial Nacional de Actividades Extremistas, AGHD.

${ }^{44}$ Entrevista a Carmen Anguita realizada por el autor, Madrid, 28 de marzo de 2019. 
Se afincaron en Palomeras Altas, Vallecas. El padre trabajaba de albañil y, por la noche, iba construyéndoles una casa baja. La madre se ocupó como señora de la limpieza. Con 7 años, Carmen se tuvo que encargar de su hermano y las tareas del hogar. En el colegio, recuerda, «te daban la leche en polvo y queso de bola. Pero clases, ninguna».

Cuando José comenzó a ir a la escuela, Carmen se puso a trabajar «porque tenía que aportar para la casa, porque no había bastante para los cuatro». Estuvo de aprendiza en tres talleres de costura. El último, de Mercedes de las Heras, era uno de alta costura con ocho empleadas. Su horario era de 10:00 a 21:00 horas. Cobraba 40 pesetas al mes. Al poco tiempo, como era muy habilidosa, pasó a ser aprendiza adelantada. Iba a entregar pedidos o a recoger hilos y muestras de tela. «Hacía de todo».

El lunes 29 de julio de 1963 la maestra le mandó a la Puerta del Sol para que le sellasen el pasaporte de su hija, que se iba de viaje al extranjero. La muchacha se sentía feliz. Hacía calor y ese día estrenaba el vestido verde que le había regalado la dueña del taller en la festividad de la Virgen del Carmen.

Llegó al Departamento de Pasaportes de la DGS a las 17:30 horas. «Había mucha gente». Hizo cola hasta que cogió su turno. Después se acomodó en un banco situado a la derecha de la entrada principal de la oficina. Al poco, cambió de sitio para situarse cerca de una columna. A su lado, contó a la Policía al día siguiente, había «un joven bien parecido físicamente», de unos 18 o 20 años. Carmen se puso a charlar con él. Eran las 17:40 cuando, citando su declaración, «oyó un ruido muy grande que ella pensó que era un cortocircuito». Se vio «volando», rememora ahora. La onda expansiva elevó su cuerpo hasta el techo. Cayó y chocó con el suelo. «Y entonces, bocabajo, me cubrí la cara. Notaba que me quemaba. Y unas convulsiones muy fuertes. “QQué me está pasando? ¿Qué pasa?” Y, bueno, estaba ardiendo. La gente me daba patadas, me pisaba, saltaba por encima de mí». Escuchó gritos, había sido una bomba. «Todo el mundo empezó a correr y yo estaba en el suelo ardiendo. Horrible, horrible».

Perdió el conocimiento solo un instante. De repente, oyó «jla niña, la niña, la niña se está quemando!». Un hombre la cogió en brazos y la evacuó al patio. La camisa blanca que llevaba «se le quedó roja de la sangre y negra de las quemaduras». Carmen esperó sentada en una silla de hierro, intentando taparse con los jirones de su vestido nuevo. Sentía «un dolor horrible». Un vehículo la trasladó al Equipo Quirúrgico. Entró en el quirófano. «Y ya no me acuerdo de más».

Según el sumario, la bomba había causado desperfectos por valor de $79.519,15$ pesetas. Los daños humanos fueron mucho mayores. En aquella sala de la DGS había más de 100 personas. 31 de ellas sufrieron heridas de diversa consideración, la mayoría de carácter leve o reservado. La peor parte se la llevaron dos mujeres: Carmen e Isabel Peña Muñoz, una comadrona granadina de 52 años. El estado de esta última era grave. «Se encontraba en la cola para gestionar el visado de salida (...) cuando sintió una explosión fenomenal, y cuando 
se recobró arrastrándose por el suelo, vio una gran humareda, y fue ayudada a levantarse por un sacerdote, puesto que las piernas no la sostenían, viéndose con sangre en los brazos, no sabiendo nada más». Carmen estaba gravísima. Le llegaron a dar la extremaunción. La bomba había estallado justo debajo de ella, volatilizando el banco de madera. Tenía seccionado parte del pie, todos los dedos abiertos y quemaduras de diverso grado en espalda, torso, brazos y piernas.

Se despertó a los dos días del atentado. En la habitación su madre y la maestra del taller lloraban. La chica se sentía «completamente abrasada». Padecía, además, shock traumático. «¡Ay, mis piernas!», se quejaba. «Nunca volveré a estar buena». No obstante, escribió un reportero, «en los momentos de mayor gravedad casi lo que más le preocupaba era que hubiera resultado destrozado el modesto traje nuevo que llevaba puesto en aquella ocasión ${ }^{45}$.

Imagen 2. Carmen Anguita en el Equipo Quirúrgico 1

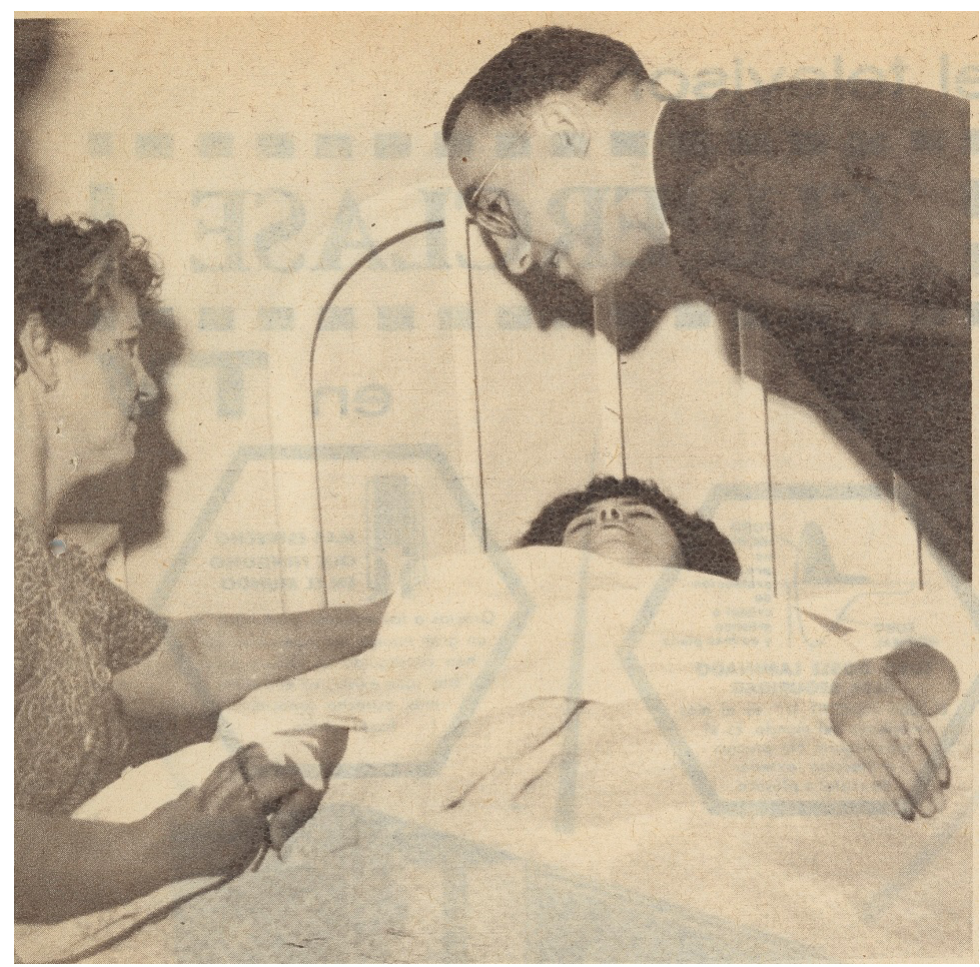

Fuente: $A B C, 31$ de julio de 1963, página 21.

${ }^{45} A B C, 31$ de julio y 18 de agosto de 1963.

Hispania, 2021, vol. LXXXI, n. ${ }^{\circ}$ 269, septiembre-diciembre, págs. 827-853, ISSN: 0018-2141, e-ISSN: 1988-8368 https://doi.org/10.3989/hispania.2021.022 
Tuvieron que hacerle un injerto y curas sistemáticas. Tardó meses en recuperarse y volver a aprender a andar. Durante ese tiempo recibió la visita de numerosos periodistas, entre los que destaca a Jesús Hermida, «que me hizo una columna muy bonita». Ciertamente, la prensa realizó un gran seguimiento de la evolución de los heridos en aquel atentado, lo que suscitó el interés de la ciudadanía. Un lector de La Vanguardia Española (Barcelona), empezó una suscripción pública para ayudar a Carmen. Se adhirieron ciudadanos, anónimos o no, empresas y el propio diario. Se reunió así un donativo de 4.638,50 pesetas, que fue entregado en septiembre de aquel mismo año ${ }^{46}$.

Tampoco faltaron las autoridades. Tras el atentado, el vicepresidente del Gobierno, el general Agustín Muñoz Grandes, había acudido al Equipo Quirúrgico, aunque no le dejaron ver a la herida porque estaba en plena operación. Ya consciente, Carmen conoció al director general de Seguridad, Carlos Arias Navarro $^{47}$. «Todos estuvieron pendientes de mí y apoyándome, interesándose». Como la muchacha vivía en una casa que ni siquiera tenía agua corriente, poco adecuada para su estado, alguno de los altos cargos del régimen que pasó por allí se encargó de que el Ministerio de la Vivienda concediera a la familia Anguita-Abril un piso moderno en Vallecas.

Cuando Carmen ya se encontraba mejor, el general Muñoz Grandes mandó un coche oficial a por ella. Quería conocerla. Le preguntó por su vida, su familia y sus estudios. La chica le confesó que apenas había recibido educación. «Y entonces me dijo: “¿Tú quieres estudiar?” Digo: "Sí, pero no puedo porque tengo que ayudar a mis padres". Dice: "Bueno, pues vas a estudiar y vamos a ayudar a tus padres"». Y así fue. Un general, de apellido Barranco, le entregaba a la familia 500 pesetas al mes. También le buscó a Carmen un centro para cursar Delineación Industrial. Lo hizo de esa manera. No se había legislado ningún tipo de ayuda especial para las víctimas del terrorismo (la primera ley de ámbito nacional data de una fecha tan tardía como 1999) ${ }^{48}$, lo que las dejaba desamparadas, pero en este caso la damnificada pudo contar con muestras del arbitrario paternalismo franquista.

Durante el verano, Carmen volvía a coser al taller de costura de Mercedes de las Heras. Además, se casó. «Yo estaba contentísima». Posteriormente compaginó las clases por la tarde con un trabajo en PPO (Promoción Profesional Obrera) por las mañanas. Se trataba de un sector muy masculinizado, apenas había mujeres. Cuando terminó su formación, permaneció en PPO «haciendo los dibujos y organigramas de los cuadernos didácticos».

${ }^{46}$ La Vanguardia, 1, 21 y 24 de agosto y 8 de septiembre de 1963. ABC, 25 de agosto de 1963.

${ }^{47}$ La Vanguardia, 1 de agosto de 1963.

${ }^{48}$ https://www.boe.es/diario_boe/txt.php?id=BOE-A-1999-20063 
Como reflejó la prensa de la época, los médicos le habían asegurado que las heridas le iban a impedir concebir ${ }^{49}$. Pero tuvo un hijo, Alberto. «Fue una sorpresa. No me lo creía. Fue un milagro».

El 13 de septiembre de 1974 ETA hizo explotar una bomba en la cafetería Rolando, en la madrileña calle de Correo, justo al lado de la DGS. Causó 13 víctimas mortales y lesiones a 73 personas ${ }^{50}$. Carmen visitó a una de ellas en cuanto se enteró de la noticia. «Fui al hospital a ver a una chiquita, que también era joven y que también tenía heridas en las piernas. Fui a verla y le di un poco de ánimo».

Más adelante el PPO fue transferido al INEM (Instituto Nacional de Empleo) y Carmen aprobó unos exámenes internos, convirtiéndose en funcionaria de carrera. «Ahí me sentí muy feliz. Yo estaba enamorada de mi trabajo. Era una profesión preciosa». Pero no todo resultó plácido en esta etapa. Los servicios centrales del INEM fueron objeto de sucesivos avisos de bomba, «casi todos, sustos». Cuando saltaba la alarma, «a mí se me ponía un temblor en las piernas, me empezaba a temblar el cuerpo y yo no atinaba a salir a la calle. Luego me tiraba dos días llorando porque era una cosa terrible». «Pero hubo un [atentado] que fue de verdad». Carmen logró escapar, cogió el coche «y cuando iba por mitad de la calle, pegó aquello un estallido que frené como pude. Me quedé en medio de la calle. Las piernas temblando. No hubo heridos graves, pero sí leves. Allí ya era ETA». Otro, mucho peor, sucedió en octubre de 2000 en el cruce de la calle de Torrelaguna con la avenida de Badajoz. Carmen conducía cuando «explotó una bomba que el coche que se me fue para los lados. "¿Qué ha pasado aquí?" Me quedé clavada. Y fue también ETA. Destrozos. Aquello fue terrible». Un coche bomba había matado a un magistrado, el general José Francisco Querol Lombardero, su escolta, el policía nacional Jesús Escudero García, y su chófer, Armando Medina Sánchez. La explosión también dejó 64 heridos. Uno de ellos, Jesús Sánchez Martínez, fallecería unos días después ${ }^{51}$. A raíz del suceso, Carmen tuvo que ir al psicólogo durante tres años.

Amaba su oficio de delineante, pero lo abandonó cuando quisieron que utilizase la informática. «Cogí un trauma muy grande. De pronto me quitaron todas las herramientas y me dijeron que me pusiera a jugar con un ordenador. Me rebelé. Dije que no». Solicitó el traslado al Ministerio de Trabajo, donde se ocupó de distintos temas. «Me sentí muy útil, pero me costó mucho». Carmen se jubiló a los 64 años, por un problema en la columna.

$49 A B C, 18$ de agosto de 1963.

${ }^{50}$ Información sobre este atentado en ALONSO, DOMÍNGUEZ IRIBARREN y GARCÍA, 2010: 40-48 y FERNÁNDEZ SOLDEVILLA, 2021: 98-102.

${ }^{51}$ El Pais, 31 de octubre de 2000. Información detallada sobre este atentado en ALONSO, DOMÍNGUEZ IRIBARREN y GARCÍA, 2010: 1084-1089. 
Todavía le quedan secuelas del atentado: perdió la audición de un oído y tiene pólvora bajo la piel. Carmen Anguita no fue reconocida como víctima del terrorismo hasta 2012, ya al amparo de la Ley 29/2011, de 22 de septiembre ${ }^{52}$. Al año siguiente se unió a la AVT (Asociación de Víctimas del Terrorismo).

Tiene dos nietos «preciosos. Me dan la vida, de verdad». En el colegio católico al que asiste, su nieto provocó cierto escándalo cuando, en plena clase de religión, contó que su abuela había resucitado. «Como Jesús».

\section{IMAGEN 3. Carmen Anguita}

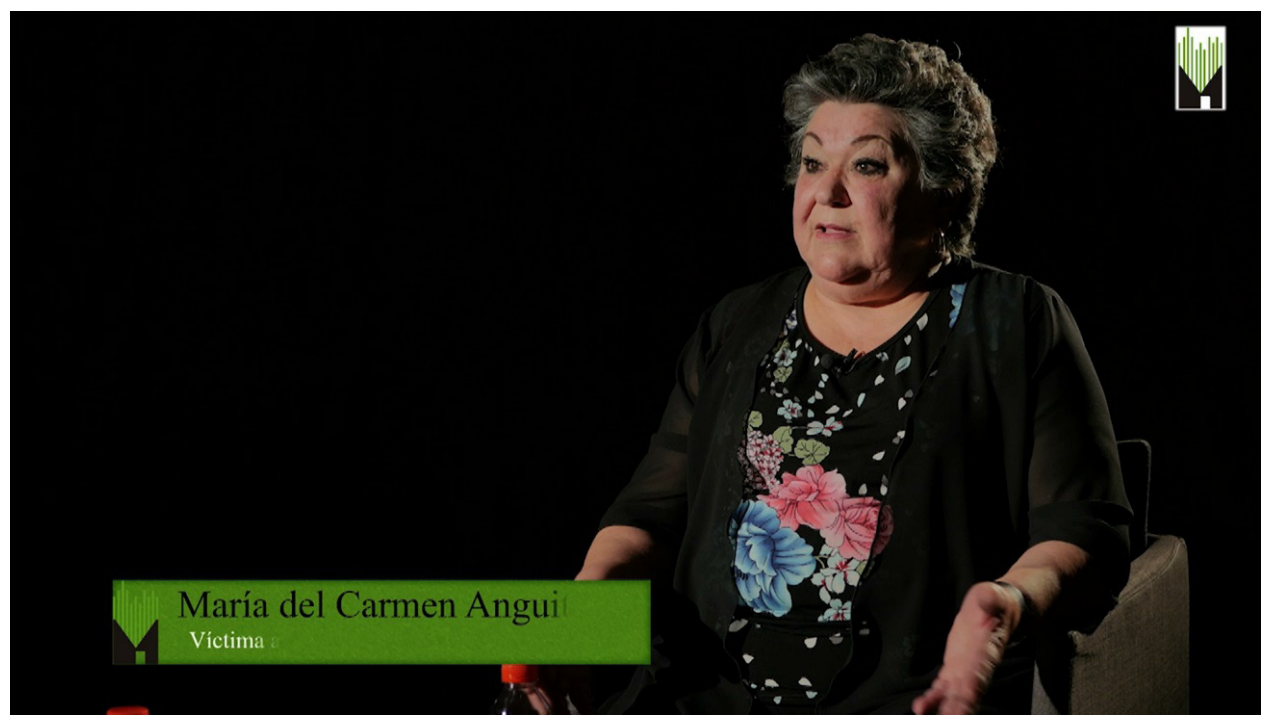

Fuente: Entrevista grabada por el autor el 28 de marzo de 2019 en Madrid, disponible en la exposición del Centro Memorial de las Víctimas del Terrorismo, Vitoria.

\section{Conclusiones}

Francisco Franco acaudilló una dictadura de corte represivo, autoritario y antidemocrático, que conculcaba los derechos más básicos de los españoles. Era un régimen ilegítimo. Sin embargo, no todas las formas de lucha contra la tiranía eran iguales ni tuvieron las mismas consecuencias.

Pese a que hacía años que el sector mayoritario de la oposición antifranquista había renunciado a la vía armada y pese a que los últimos restos de la

${ }^{52}$ Lo había solicitado con anterioridad, pero le había sido denegado porque la legislación no abarcaba hasta la fecha de su atentado. 
guerrilla acababan de desaparecer, el movimiento libertario creó una organización para reactivar la lucha violenta. Por medio de las bombas, Defensa Interior aspiraba a acabar con la dictadura y con la vida del dictador. Cosechó un absoluto fracaso. Ni Franco ni su régimen se vieron mínimamente afectados por aquellos atentados.

La violencia no solo fue inútil, sino que, desde la perspectiva libertaria, también fue contraproducente. Dio argumentos al gobierno franquista para justificar la represión policial y puso en peligro el estatus de los anarquistas exiliados en Francia. La trayectoria de Defensa Interior es un ejemplo que confirma la tesis central de la obra colectiva: When Does Terrorism Work?, dirigida por Diego Muro: los grupos que adoptan una estrategia violenta, lejos de lograr sus objetivos, suelen perjudicarlos ${ }^{53}$.

De alguna manera, el descalabro de la vía armada del DRIL y de Defensa Interior dio la razón a las fuerzas antifranquistas tradicionales, que mantenían una posición más realista respecto a la utilidad de la vía armada, fruto de la experiencia del maquis. También sugería que el impulso del exilio se estaba agotando. La oposición que había surgido en el interior de España, que tenía su propia estrategia y menos lastres heredados del pasado, tomaba el relevo: sindicatos clandestinos, movimientos sociales, nuevos partidos políticos, etc. Es cierto que protestas, huelgas o manifestaciones tampoco derribaron al régimen, pero lo fueron debilitando y, a la postre, contribuyeron a poner las bases sobre las que en 1977 se restauraría la democracia parlamentaria.

Por supuesto, hubo excepciones. La más llamativa fue ETA. Esta organización nació a mediados de 1959, prácticamente a la vez que el DRIL, Defensa Interior y otros grupúsculos similares, con los cuales tenía bastantes rasgos en común, como la edad de muchos de sus miembros, el choque con la generación anterior, el rechazo a las instituciones republicanas o el intento de emular la revolución castrista ${ }^{54}$. Ahora bien, al contrario que sus coetáneos, ETA consiguió consolidarse e ir adaptándose a la cambiante coyuntura: sobrevivió hasta 2018. Tal divergencia solo se explica si ponemos el foco en los elementos que diferenciaban a la banda: una doctrina muy cohesionada, el nacionalismo vasco radical, que servía de aglutinante a sus militantes; un antifranquismo meramente accidental, por lo que se enfrentó a la Transición democrática sin excesivas contradicciones internas; un modelo organizativo eficaz ante la actuación policial; buenas fuentes de financiación, como los atracos, los secuestros y la extorsión; una retaguardia segura, el País Vasco francés; y un entorno político y social entregado, que le ha servido de apoyo, legitimación y oficina de reclu-

53 MURO, 2018.

${ }^{54}$ Sobre la primera ETA véanse FERNÁNDEZ SOLDEVILLA, 2016 y PABLO, 2019. 
tamiento. La prolongada trayectoria terrorista de ETA arroja un saldo de 853 asesinatos y más de 2.600 heridos $^{55}$.

A su lado, la violencia de Defensa Interior queda empequeñecida, pero no debe ser ignorada. Sus miembros causaron la muerte a una persona y lesiones a otras 35. A lo largo de estas páginas hemos intentado reconstruir la biografía de dos de las víctimas de esta organización. La primera, Manuel Eleuterio Liáñez, era un anciano al borde de la miseria que durante la Guerra Civil había utilizado su cargo en la CNT para salvar la vida de un hombre de derechas. La segunda, Carmen Anguita, era una joven aprendiza de modista, de familia humilde y sin estudios. Sus historias ilustran hasta qué punto el terrorismo es trágico, brutal y completamente injustificable. Tienen, por tanto, una dimensión universal. En palabras del filósofo Manuel Reyes Mate, «si alguien reconoce a una víctima, tiene que reconocer a todas $\rangle^{56}$.

La memoria de Manuel Eleuterio Liáñez y Carmen Anguita también arroja luz sobre la responsabilidad histórica de quienes ejercieron la violencia. Adoptamos aquí la perspectiva de la profesora Martha Crenshaw, quien, desde su ya clásico artículo de 1981, ha defendido que, en cuanto actor racional colectivo, cada organización escoge intencionadamente su estrategia para conseguir sus metas. El terrorismo es solo uno entre los muchos caminos posibles. Es innegable que tal decisión se toma bajo la influencia de unas circunstancias muy concretas (en este caso, la dictadura franquista), pero hay que descartar el determinismo histórico, la mera contextualización o las teorías monocausales. En definitiva, el grupo opta por este tipo de violencia conscientemente, tras desechar otras alternativas que creen más costosas o menos efectivas para sus propósitos ${ }^{57}$. Eso es lo que ocurrió en el II Congreso Intercontinental de Limoges en 1961. Por la misma razón, el movimiento libertario español pudo echarse atrás en el Congreso de Montpellier de 1965.

La respuesta del régimen franquista a los atentados terroristas fue implacable. Los detenidos (activistas de Defensa Interior, pero también anarquistas o antifranquistas que poco o nada tenían que ver con ellos) fueron condenados a largas condenas de cárcel. Un par de integrantes de un comando, Joaquín Delgado y Francisco Granado, fueron condenados a muerte por un crimen que no habían cometido. El proceso judicial y la posterior ejecución de aquellas dos personas son una muestra evidente de que, pese a que en aquella fase se había

${ }^{55}$ Sobre las víctimas de esta banda terrorista, véase ALONSO, DOMÍNGUEZ IRIBARREN y GARCÍA, 2010. Sobre su historia, ELORZA, 2000. UGARTE, 2018. LÓPEZ ROMO, 2015. FERNÁNDEZ SOLDEVILLA y DOMÍNGUEZ IRIBARREN, 2018. Sobre su final, véanse DOMÍNGUEZ IRIBARREN, 2017, FERNÁNDEZ SOLDEVILLA, 2021: 189208 y el número monográfico de la revista Grand Place (Zarauz, 2021), disponible en https:// marioonaindiafundazioa.org/

${ }^{56}$ MATE, 2013: 281.

${ }^{57}$ CRENSHAW, 1981; 2011. 
mitigado, la violencia represiva nunca desapareció: fue un instrumento recurrente del franquismo.

La dictadura mostró una cara contradictoria ante las víctimas de Defensa Interior. Más allá del impacto momentáneo del atentado que le costó la vida, ni la prensa ni las autoridades se interesaron por Manuel Eleuterio Liáñez. Su nombre apareció fugazmente en los periódicos para ser rápidamente olvidado. Tal vez esta dejadez estaba relacionada con el historial delictivo de la víctima, cuando no con su antigua militancia en la CNT. La figura de Liáñez no encajaba en el discurso triunfalista del régimen.

Por otra parte, aunque pronto se arrestó a miembros de Defensa Interior, no se les llegó a acusar del crimen, que quedó impune. Por una sencilla razón: no había pruebas sólidas sobre la identidad de los autores materiales. Ahora bien, tampoco las había en los casos de las bombas del Valle de los Caídos y de la DGS, pero no se dudó en imputárselas a tres detenidos a los que se condenó sin pruebas sólidas.

El atentado de la DGS acaparó la atención de los medios de comunicación, de altos cargos de la dictadura y de un sector de la sociedad española durante bastante tiempo. Fue instrumentalizado propagandísticamente por el franquismo, que pudo presentar a los terroristas como una peligrosa amenaza externa desestabilizadora. De entre todas las víctimas, se concedió un especial protagonismo a Carmen Anguita. Ella era la herida más grave, cierto, pero también una chica simpática, con atractivo y con un pasado impoluto. Despertó la compasión de lectores, periodistas e incluso del vicepresidente del Gobierno, el general Agustín Muñoz Grandes, quien ayudó a Carmen y a su familia. Lo hizo desinteresadamente, lejos de las cámaras de los fotógrafos, pero de una manera paternalista. Y arbitraria: otras víctimas del terrorismo no tuvieron tanta suerte.

Una última reflexión. Desde el punto de vista historiográfico, es necesario avanzar en el conocimiento acerca del pasado, incluyendo aquellos episodios más oscuros e incómodos. Se trata de cumplir una función similar a la de otras disciplinas académicas. En el caso de investigaciones sobre violencia política, a esta dimensión científica hay que sumar otras propias de la función social del historiador. Siguiendo al ensayista Martín Alonso, recuperar y difundir la memoria de los damnificados por el terrorismo es beneficioso para el conjunto de la ciudadanía. Por un lado, responde a una misión reparadora y terapéutica para las víctimas y sus seres queridos. Por otro, el recuerdo tiene un papel proactivo y profiláctico: es una vacuna contra el fanatismo, la radicalización y la fascinación por las armas; el estímulo de una sociedad cívica, democrática y tolerante ${ }^{58}$.

\footnotetext{
58 ALONSO, 2012: 193-194.
} 


\section{BiBliografíA}

Alberola, Octavio, «El D.I.: la última tentativa libertaria de lucha armada contra el régimen de Franco», en VV. AA., La oposición libertaria al régimen de Franco. Memorias de las III Jornadas Internacionales de Debate Libertario, Madrid, Fundación Salvador Seguí, 1993: 343-387.

Alberola, Octavio y Gransac, Ariane, El anarquismo español y la acción revolucionaria (1961-1974), Barcelona, Virus, 2004.

Alberola, Octavio y Villagrasa i Hernàndez, Félix, «Resumen histórico del Grupo pro revisión del proceso Granado-Delgado», Hispania Nova, 7 (2007).

Alonso, Martín (coord.), El lugar de la memoria. La huella del mal como pedagogía democrática, Bilbao, Bakeaz, 2012.

Alonso, Rogelio, Domínguez Iribarren, Florencio y García, Marcos, Vidas rotas. Historia de los hombres, mujeres y niños víctimas de ETA, Madrid, Espasa, 2010.

Avilés, Juan, El terrorismo en España: de ETA a Al Qaeda, Madrid, Arco Libros, 2010.

Avilés, Juan, La daga y la dinamita. Los anarquistas y el nacimiento del terrorismo, Barcelona, Tusquets, 2013.

Avilés, Juan, Azcona, José Manuel y Re, Matteo, Después del 68: la deriva terrorista en Occidente, Madrid, Silex, 2019.

Avilés, Juan y Herrerín, Ángel (coords.), El nacimiento del terrorismo en Occidente. Anarquí, nihilismo y violencia revolucionaria, Madrid, Siglo XXI, 2008.

Batista, Antonio, Matar a Franco. Los atentados contra el dictador, Barcelona, Debate, 2015.

Castro Moral, Lorenzo, Retablo de conspiradores. El exilio republicano y la tentación de la violencia (1958-1964), trabajo inédito.

Christie, Stuart, Franco me hizo terrorista. Memorias del anarquista que intentó matar al dictador, Madrid, Temas de Hoy, 2005.

Crenshaw, Martha, «The Causes of Terrorism», Comparative Politics, 13 (Nueva York, 1981): 379-399.

Crenshaw, Martha, Explaining Terrorism: Causes, Processes, and Consequences, Londres / Nueva York, Routledge, 2011.

Domínguez Iribarren, Florencio, «Las claves de la derrota de ETA», Informe del Centro Memorial de las Victimas del Terrorismo, 3 (Vitoria, 2017), disponible en http://www.memorialvt.com/publicaciones/

Edo, Luis Andrés, La CNT en la encrucijada. Aventuras de un heterodoxo, Barcelona, Flor del Viento Ediciones, 2006.

Elorza, Antonio (coord.), La historia de ETA, Madrid, Temas de Hoy, 2000.

Espinosa Maestre, Francisco (coord.), Violencia roja y azul. España, 1936-1950, Barcelona, Crítica, 2010.

Fernández Soldevilla, Gaizka, La voluntad del gudari. Génesis y metástasis de la violencia de ETA, Madrid, Tecnos, 2016.

Fernández Soldevilla, Gaizka, El terrorismo en España. De ETA al Dáesh, Madrid, Cátedra, 2021. 
Fernández Soldevilla, Gaizka y Aguilar, Manuel, «Muerte en Amara. La violencia del DRIL a la luz de Begoña Urroz», Informe del Centro Memorial de las Víctimas del Terrorismo, 6 (Vitoria, 2019), disponible en http://www.memorialvt.com/ publicaciones/

Fernández Soldevilla, Gaizka y Domínguez Iribarren, Florencio (coords.), Pardines. Cuando ETA empezó a matar, Madrid, Tecnos, 2018.

Fonseca, Carlos, Garrote vil para dos inocentes. El caso Delgado-Granado, Madrid, Temas de hoy, 1998.

González Calleja, Eduardo, El laboratorio del miedo. Una historia general del terrorismo, de los sicarios a Al Qu’ida, Barcelona, Crítica, 2013.

González Calleja, Eduardo, Asalto al poder. La violencia politica organizada y las ciencias sociales, Madrid, Siglo XXI, 2017.

Gurucharri, Salvador e Ibáñez, Tomás, Insurgencia libertaria. Las Juventudes Libertarias en la lucha contra el franquismo, Barcelona, Virus, 2010.

Herrerín, Ángel, La CNT durante el franquismo. Clandestinidad y exilio (1939-1975), Madrid, Siglo XXI, 2004.

Herrerín, Ángel, Defensa interior: el fin de la violencia libertaria, en Abdon Mateos y Ángel Herrerín (coords.), La España del presente: de la dictadura a la democracia, Madrid, Asociación de Historiadores del Presente, 2006: 25-38.

Íñiguez, Miguel, Enciclopedia histórica del anarquismo español, Vitoria, Asociación Isaac Puente, 2008.

Jiménez, María, «Escribir sobre las víctimas: la bibliografía dedicada a los asesinados por ETA», e-Eguzkilore, 2 (San Sebastián, 2017).

Jiménez, María, «El rostro humano de las víctimas: relatos personales ante la tragedia», en Gaizka Fernández Soldevilla y María Jiménez, 1980. El terrorismo contra la Transición, Madrid, Tecnos, 2020: 277-306.

Jiménez, María y Marrodán, Javier, Heridos y olvidados: los supervivientes del terrorismo en España, Madrid, La Esfera de los Libros, 2019.

López Romo, Raúl, Informe Foronda. Los efectos del terrorismo en la sociedad vasca, Madrid, Los Libros de la Catarata, 2015.

Mate, Manuel Reyes, Justicia de las víctimas y reconciliación en el País Vasco, Madrid, Documento de trabajo de la Fundación Alternativas, 2006, disponible en https://www.fundacionalternativas.org/laboratorio/documentos/seminarios-y-jornadas/ justicia-de-las-victimas-y-reconciliacion-en-el-pais-vasco

Mate, Manuel Reyes, La piedra desechada, Madrid, Trotta, 2013.

Moradiellos, Enrique, Franco. Anatomía de un dictador, Madrid, Turner, 2018.

Muro, Diego (ed.), When Does Terrorism Work?, Nueva York, Routledge, 2018.

Ortiz Heras, Manuel, «Control social y represión en la dictadura franquista», en Abdón Mateos (coord.), La España de los cincuenta, Madrid, Eneida, 2008: 15-44.

Pablo, Santiago de, «Julio de 1959: El nacimiento de ETA», Historia Actual Online, 48 (Cádiz, 2019): 45-59.

Rapoport, David C., «Four waves of modern terrorism», en Audrey Kurth Cronin y James M. Ludes (coords.), Attacking terrorism: elements of a grand strategy, Washington, Georgetown University, 2004: 46-73. 
Serrano, Secundino, Maquis. Historia de la guerrilla antifranquista, Madrid, Temas de Hoy, 2001.

Ugarte, Josu (coord.), La bolsa y la vida. La extorsión y la violencia de ETA contra el mundo empresarial, Madrid, La Esfera de los Libros, 2018.

Recibido: $27 / 09 / 2019$

Aceptado: 26/08/2020 